\title{
Correction to: Beyond one-way determinism: San Frediano's miracle and climate change in Central and Northern Italy in late antiquity
}

Giovanni Zanchetta ${ }^{1,2,3} \cdot$ Monica Bini ${ }^{1,3,4} \cdot$ Kevin Bloomfield ${ }^{5} \cdot$ Adam Izdebski $^{6,7}$.

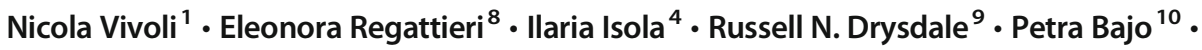
John C. Hellstrom ${ }^{11} \cdot$ Robert Wiśniewski $^{12} \cdot$ Anthony E. Fallick ${ }^{13} \cdot$ Stefano Natali $^{14}$. $^{14}$ Marco Luppichini ${ }^{14}$

A Correction to this paper has been published: https://doi.org/10.1007/s10584-021-03087-z Corrections to: Climatic Change https://orcid.org/10.1007/s10584-021-03043-X

The original article has been corrected. During proof correction of the article, mistakes in the author affiliations of Petra Bajo, John C. Hellstrom, Robert Wiśniewski, Anthony E. Fallick, Stefano Natali, and Marco Luppichini were introduced. Please find the correct affiliations here as well.

Petra Bajo: Department of Mineral Resources, Croatian Geological Survey, 10000, Zagreb, Croatia

John C. Hellstrom: School of Earth Sciences, The University of Melbourne, Melbourne, VIC, 3010, Australia

Robert Wiśniewski: Faculty of History, University of Warsaw, Warsaw, Poland

Anthony E. Fallick: Scottish Universities Environmental Research Centre, SUERC, East Kilbride, UK

Stefano Natali: Dipartimento di Scienze della Terra, University of Florence, Florence, Italy Marco Luppichini: Dipartimento di Scienze della Terra, University of Florence, Florence, Italy

The online version of the original article can be found at https://doi.org/10.1007/s10584-021-03043-X

Adam Izdebski

izdebski@ shh.mpg.de

Extended author information available on the last page of the article 
Publisher's note Springer Nature remains neutral with regard to jurisdictional claims in published maps and institutional affiliations.

\section{Affiliations}

Giovanni Zanchetta ${ }^{1,2,3} \cdot$ Monica Bini ${ }^{1,3,4} \cdot$ Kevin Bloomfield ${ }^{5} \cdot$ Adam Izdebski $^{6,7}$. Nicola Vivoli ${ }^{1}$ - Eleonora Regattieri ${ }^{8}$ - Ilaria Isola ${ }^{4} \cdot$ Russell N. Drysdale $^{9} \cdot$ Petra Bajo $^{10}$. $^{2}$ John C. Hellstrom ${ }^{11} \cdot$ Robert Wiśniewski $^{12}$ - Anthony E. Fallick ${ }^{13} \cdot$ Stefano Natali $^{14}$. $^{14}$ Marco Luppichini ${ }^{14}$

Dipartimento di Scienze della Terra, University of Pisa, Pisa, Italy

2 Istituto di Geologia Ambientale e Geoingegneria, IGAG-CNR, Rome, Italy

3 Centre for Climatic Change Impact CIRSEC University of Pisa, Pisa, Italy

4 Istituto Nazionale di Geofisica e Vulcanologia, INGV Sez. Pisa, Pisa, Italy

5 Department of History, Cornell University, Ithaca, NY, USA

6 "Palaeo-Science \& History"Independent Research Group, Max Planck Institute for the Science of Human History, Jena, Germany

7 Institute of History, Jagiellonian University, Krakow, Poland

8 Istituto di Geoscienze e Georisorse, IGG-CNR, Pisa, Italy

9 School of Geography, The University of Melbourne, Melbourne, Australia

10 Department of Mineral Resources, Croatian Geological Survey, 10000 Zagreb, Croatia

11 School of Earth Sciences, The University of Melbourne, Melbourne, VIC 3010, Australia

12 Faculty of History, University of Warsaw, Warsaw, Poland

13 Scottish Universities Environmental Research Centre, SUERC, East Kilbride, UK

14 Dipartimento di Scienze della Terra, University of Florence, Florence, Italy 